Michael Joannidis Wilfred Druml Lui G. Forni A. B. Johan Groeneveld Patrick Honore Heleen M. Oudemans-van Straaten Claudio Ronco Marie R. C. Schetz Arend Jan Woittiez

\section{Erratum to: Prevention of acute kidney injury and protection of renal function in the intensive care unit}

\section{Expert opinion of the working group for nephrology, ESICM}

Published online: 23 February 2010

(C) Copyright jointly held by Springer and ESICM 2010

The online version of the original article can be found under doi:10.1007/s00134-009-1678-y.

\section{Joannidis ( $\bullet$ )}

Medical Intensive Care Unit,

Department of Internal Medicine I,

Medical University Innsbruck,

Anichstasse, 31, 6020 Innsbruck, Austria

e-mail: michael.joannidis@i-med.ac.at

Tel.: +43-512-50424180

Fax: +43-512-50424202

\section{W. Druml}

Department of Internal Medicine III,

University Hospital Vienna, Vienna, Austria

L. G. Forni

Western Sussex Hospitals Trust,

Brighton and Sussex, Medical School,

University of Sussex, Brighton, UK

\section{A. B. J. Groeneveld}

Department of Intensive Care, VU Medical Center,

Amsterdam, The Netherlands

P. Honore

Department of Intensive Care, Burn Center, Queen Astrid Military Hospital,

Neder-Over-Heembeek (Brussels), Belgium

H. M. Oudemans-van Straaten

Department of Intensive Care Medicine,

Onze Lieve Vrouwe Gasthuis,

Amsterdam, The Netherlands
C. Ronco

Department of Nephrology Dialysis and Transplantation, San Bortolo Hospital, Viale Rodolfi 37, Vicenza, Italy

M. R. C. Schetz

Department of Intensive Care Medicine, University Hospital, Catholic University, Leuven, Leuven, Belgium

\author{
A. J. Woittiez \\ Division of Nephrology, Department of Medicine, \\ University Medical Center, Groningen, \\ University of Groningen, Groningen, The Netherlands
}

\section{Erratum to: Intensive Care Med DOI 10.1007/s00134-009-1678-y}

Last sentence of the abstract unfortunately contained a mistake.

It should read:

We suggest specific vasodilators under strict hemodynamic control, sodium bicarbonate for emergency procedures administering contrast media, and periprocedural hemofiltration in severe chronic renal insufficiency undergoing coronary intervention. 